\title{
DONA DE CASA OU DONA DE SI? UM ESTUDO SOBRE A REPRESENTAÇÃO FEMININA EM PRODUTOS DE LIMPEZA E ALIMENTÍ́CIOS
}

\author{
HOUSEWIFE? OR OWNER OF YOU? A STUDY ON \\ FEMALE REPRESENTATION IN CLEANING AND FOOD \\ PRODUCTS
}

Ricardo Santos David*

Resumo: Este trabalho visa discutir a imagem do feminino, com base no percurso da mulher e suas conquistas na sociedade e no mercado de trabalho. Assim sendo, nosso objetivo principal é compreender o papel da mulher na publicidade, ou seja, a construção da identidade feminina em propagandas antigas e atuais, em anúncios publicitários de produtos de limpeza. Para análise, portanto, selecionamos sete propagandas impressas desde os anos 50 até os anos 2000, que utilizam a imagem da mulher para a divulgação comercial dos produtos de limpeza. A investigação é baseada nos pressupostos teóricos de Priore (2000), Strey (1997) e Confortin (2003) para o levantamento do percurso histórico da mulher, suas conquistas e evoluções na sociedade, no mercado de trabalho, em casa e, principalmente, no universo feminino. Para as análises discursivas, utilizamos a perspectiva do Círculo de Mikhail Bakhtin sobre dialogismo e gêneros do discurso, em particular, a concepção de estilo. No que se refere à publicidade e propaganda, baseamo-nos nos estudos de Iasbeck (2002) sobre o slogan e de Baudrillard (2002) que vincula sociologia à semiologia. Desse modo, buscamos compreender a finalidade da utilização da imagem da mulher veiculada nas propagandas de limpeza, assim como os diálogos presentes e as diferentes vozes inseridas numa análise de propagandas que apresentam temáticas reiteradas ou diversas a cada década.

Palavras-Chave: Identidade feminina, Dialogismo, Anúncio publicitário, Gêneros publicitários, Figura feminina, Produtos de limpeza e alimentícios, Ethos.

AвSTRACT: The aim of this research is to discuss the female image based on the path of woman and their achievements in society and the labor market. Hence, our main objective is to comprehend the role of woman in publicity genre, in other words, the construction of female identity in former and current advertisements for cleaning

\footnotetext{
"Pesquisador, Professor, Orientador, Coordenador Ciências da Língua (gem). Pós - Doutorado em Educação: Psicanálise. Doutor e Mestre em Comunicação e Educação. Uniatlántico. IESLA. FCU - EUA. UCAM. UNOESTE. Revisor de Textos. Analista de Comunicação e Redator. Email: ricardosdavid@hotmail.com
} 
products. For analysis, therefore, we selected seven print advertisements from the 50 s to the 2000 s, that use the image of woman for commercial dissemination of cleaning products. The research is based on theoretical assumptions of Priore (2000), Strey (1997) and Confortin (2003) who support the historical path of woman, their achievements and developments in society, in the labor market, at home and mainly, in the female universe. For the discursive analysis, we use the reflections of Bakhtin's Circle on dialogism and discourse genres, specially, the conception of style. In relation to publicity and advertising, our research was based on the studies of Iasbeck (2002) about the slogan and of Baudrillard (2002) who links sociology to semiology. Therefore, we seek to comprehend the purpose of use of the image of woman in cleaning products advertisements, as well as the dialogues and the different voices inserted in the analysis of advertisements that present thematic reiterated or diverse themes in each decade.

KeYwords: Female identity, Dialogism, Advertisements, Publicity genres, Female figure, Cleaning products and foods, Ethos.

\section{INTRODUÇÃO:}

$\mathrm{Na}$ sociedade, desde os tempos mais antigos até a atualidade, existiram grande diferenças apresentadas entre o homem e a mulher. O termo "sexo" era utilizado para distinguir o homem da mulher, mas com o passar do tempo essa atribuição foi dada ao gênero que tem como função tratar a identidade atribuída a uma pessoa de acordo com seu caráter biológico, sendo o gênero feminino para a mulher e masculino para o homem. A mulher, como já apresentamos anteriormente, sempre foi considerada um ser menos privilegiado que o homem, teve menos direitos e até mesmo foi tratada como um ser inferior em relação ao homem, ou seja, deveria ser completamente submissa e destinada somente ao lar com o papel de esposa/mãe.

Entretanto, com passar do tempo, a figura feminina ganhou espaço e foi se modificando pouco a pouco.

A partir dos anos 50, iniciaram-se os primeiros movimentos feministas com a propagação da mulher no mercado de trabalho e, é a partir desse momento, que as primeiras agências de propagandas foram instaladas no Brasil (CONFORTIN, 2003). Houve uma grande repercussão nesse período, pois grande parte das propagandas tratavam da imagem feminina ou se dirigia como foco principal. Os anúncios buscavam introduzir hábitos da higiene, saúde, beleza e cuidados com o lar, sendo voltados para o público feminino com o intuito de tratar a modernidade e praticidade, como propagandas comerciais de cosméticos, cigarros, produtos de limpezas e eletrodomésticos.

Durante o processo da "criação da identidade feminina", a publicidade teve e tem um papel fundamental, pois apresentou valores, mudanças e desenvolvimento da imagem feminina desde tempos antigos até a atualidade.

Com a propaganda, a mulher passou a ser público-alvo de consumo, devido às novas tecnologias que eram oferecidas e apresentadas, facilitando, assim, sua vida por meio dos produtos oferecidos e tornando-a uma mulher moderna da época. Tudo começou 
quando o ferro a vapor passou a ser substituído pelo ferro elétrico, o fogão preparado a lenha pelo fogão a gás, a batedeira, a enceradeira, o liquidificador, o tanquinho, secador de cabelos, aspirador de pó, panelas de pressão e os produtos de embalagens plásticas trouxeram à vida das donas de casa um grande conforto e praticidade. Por meio da inserção de novos produtos e da tecnologia, as mulheres passaram a ganhar mais tempo e espaço no mundo, pois foi nessa época que a mulher conquistou mais espaço no mercado de trabalho, deixando, assim, de ser apenas a mulher dona de casa e se tornando ao mesmo tempo, a dona de casa, mãe, mulher moderna, trabalhadora. Outros produtos que tiveram papel fundamental no crescimento da identidade feminina foram os de limpeza. Com o surgimento do sabão em pó, detergente, amaciante e esponjas de aço, as donas de casa se sentiram muito mais satisfeitas com os resultados, pois agradavam a todos os membros da família com a casa arrumada e roupas perfumadas, porém com um diferencial, suas atividades eram realizadas com mais facilidades e em menor tempo de produção. Além da limpeza e do trabalho, a mulher passou a se preocupar mais com a estética, ou melhor, dizendo, a mulher passou a ter tempo para se preocupar com a aparência e também com o vestuário. Produtos como cremes, pó de arroz, batom, blush e rímel tornaram-se fundamentais para a valorização da imagem feminina e também passaram a serem objetos de consumo indispensáveis. Todos esses tipos de produtos foram inseridos no cotidiano feminino, por meio da publicidade, pois as propagandas buscavam mostrar tudo o que as mulheres desejavam ou que faltava em sua vida e por meio do poder de persuasão atingiam o público com grande facilidade. Esses discursos eram apresentados de forma comovente ou direta, apresentando ao consumidor o porquê daquele determinado produto não poder fica fora de sua vida:

A vida da mulher se transformou muito de quarenta anos para cá. Se na década de 60 ela cuidava dos filhos e da casa, hoje faz isso e muito mais. Trabalha ganha seu próprio dinheiro, tem poder de consumo para comprar sua casa, seu carro... Porém, ainda existe uma cultura machista no Brasil. A publicidade reproduz essa cultura frequentemente (GARBOGGINISIQUEIRA, 1995, p. 141).

Por volta da década de 60, quando surgiu a revista Claudia, a mulher brasileira também começou a demonstrar os seus primeiros passos de mudanças. A própria revista promovia debates ao tratar de temas polêmicos como divórcio, pílulas anticoncepcionais, sexo, aborto, crescimento profissional, dicas de maquiagem, moda e emagrecimento entre outros temas considerados como modernos e inovadores. A meta da revista era despertar desejo por transformações que levassem à mulher realizadora e ativa.

Porém muitas vezes os artigos destas publicações eram escritos por homens, já que as mulheres ainda não estavam inseridas no mercado de trabalho. Por isso, os temas abordados eram quase sempre machistas ou voltados para a felicidade conjugal. As revistas femininas de 1950 e 1960 expressavam pontos de vista masculinos sobre como 
as mulheres deveriam agir. As publicações femininas brasileiras abordavam o amor entre os casais e as obrigações das mulheres para manter o casamento.

\section{VEJA ABAIXO EXEMPLOS DE FRASES DAQUELA ÉPOCA PUBLICADOS NA REVISTA:}

"A mulher deve estar ciente de que dificilmente um homem pode perdoar uma mulher por não ter resistido às experiências pré-nupciais, mostrando que era perfeita e única, exatamente como ele a idealizara. (Revista Claudia, 1962).

Ainda assim a busca pela liberdade, desenvolvimento profissional e intelectual também começou por meio de movimentos feministas do mundo ocidental. A partir desse momento, as mulheres emanciparam-se e conquistaram maior liberdade de decisão, maior espaço, passaram a se preocupar mais com a aparência e com o bem-estar de si próprias, sem deixar de lado seus afazeres e deveres. Assim, construiu-se, aos poucos a imagem dessa mulher mais independente $\mathrm{e}$ retratada na publicidade.

Como o passar do tempo, a mulher realizou outra conquista, passou a ser símbolo representativo de marketing, trabalhando em propagandas e anúncios.

As propagandas, muitas vezes, construíram a imagem feminina, como a mulher esposa, mãe, dona de casa (doméstica) e trabalhadora, pois passou a ter o direito de trabalhar e obter seu próprio salário, ou com a imagem da mulher jovem, solteira e bela que não era apenas considerada como um padrão de beleza e também como ícone importante que cativava grande parte do olhar masculino. Como já mencionamos, a mulher entrou para o mercado de trabalho, aumentando, assim, a sua participação no poder econômico. As empresas começaram a focar-se no papel que a mulher tinha na sociedade e a investir em publicidade que se adequasse e encaixasse ao perfil feminino. Os anúncios enfatizavam essa função como benéfica e como uma conquista feminina, pois mostravam a imagem da mulher feliz ao manusear um eletrodoméstico ou um produto de limpeza. Em outro, exibiam a mulher perfeita ao utilizar o cosmético proposto pela propaganda, configurando a imagem de uma mulher independente e mais feminina (CONFORTIN, 2003).

\section{Reflexõ NA PERSPECTIVA BAKHTINIANA}

Os gêneros, de modo geral, contribuem para estabilizar, classificar e ordenar as atividades comunicativas pertencentes ao dia a dia das pessoas são enunciados que podem modificar com o tempo ou até mesmo desaparecerem em função das necessidades e das diferentes esferas da utilização da língua. Segundo (BAKHTIN, 2003, p. 262), "cada enunciado particular é individual, mas cada campo de utilização da lingua elabora seus tipos relativamente estáveis de enunciados, os quais denominamos gêneros do discurso". Nesse contexto, os gêneros do discurso são infinitos, pois a variedade da atividade humana é inesgotável, e cada esfera dessa atividade comporta um repertório de gêneros do discurso que vai diferenciando-se e ampliando-se, à medida que a própria esfera se desenvolve e fica mais complexa.

As propagandas de produtos de limpeza, na maioria das vezes, colocou a mulher como público-alvo principal. Sua participação era e ainda é de grande importância para 
esse tipo de publicidade, pois é a responsável pelas tarefas de limpeza e de manutenção da casa, e que ainda está, em grande proporção, a cargo delas, tornando, assim, símbolo de representação para esse tipo de mercado e comércio. Mesmo na atualidade, em que, em alguns casos, as despesas e as tarefas domiciliares são divididas entre marido e esposa, a mulher ainda é considerada fundamental e até mesmo insubstituível, para lavar, passar, cozinhar, limpar e pela organização geral.

Durante muito tempo, a mulher passou a ser objeto de posse do homem e necessitava cumprir os padrões exigidos da época, para ser considerada a esposa ideal, tendo como função restrita ao mundo doméstico, ou seja, era submissa ao seu marido e filhos. Quando alguma mulher quebrava esses dogmas, era marginalizada, discriminada e vítima de preconceitos. Desde a infância, as mulheres eram preparadas para o casamento, aprendendo muito cedo a cozinhar, costurar, limpar e a ser uma boa esposa. A mãe era responsável por ensinar e "moldar" sua(s) filha(s), de acordo com os padrões exigidos e instituídos, além de "vigiá-las" para manter a virgindade que, na época, era considerada como um status da noiva.

Era esse o tipo de perfil feminino retratado na publicidade da década de 50. A imagem apresentada era a figura feminina que se dedicava apenas aos cuidados da casa e família, que não tinha muitas vaidades com a aparência física, pois estava focada apenas nos membros familiares.

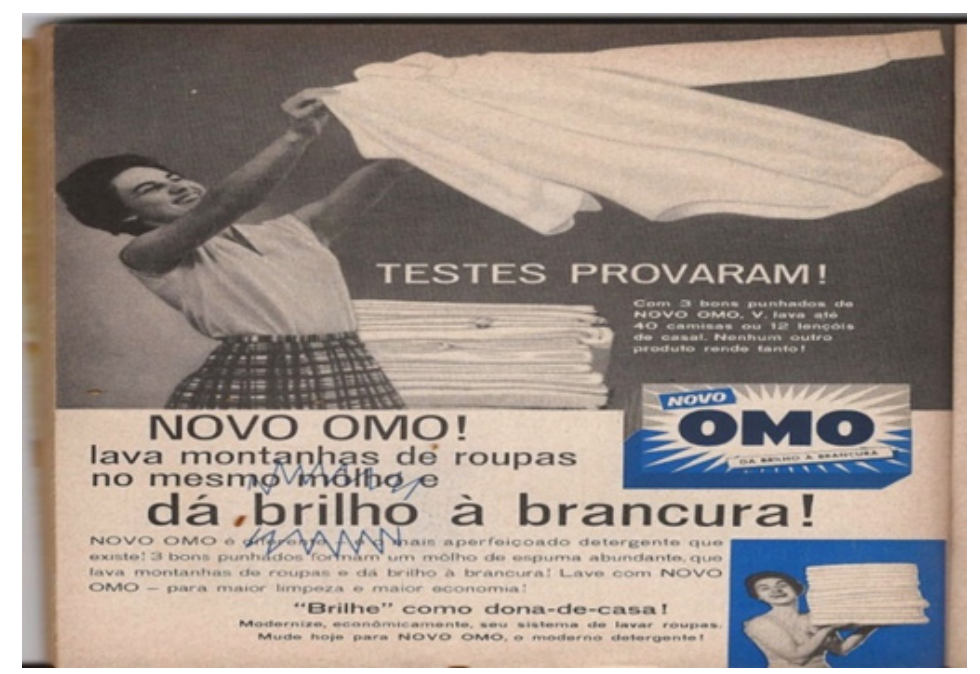

Fonte: https://produto.mercadolivre.com.br/MLB-748655081-propaganda-antiga-sabo-em-po-omo1962-detergente-roupas-1-_JM

†

NOVO OMO é diferente-E o mais aperfeiçoado que existe! 03 bons punhados formam um molho de espuma abundante, que lava montanhas de roupas e dá brilho à brancura! Lave com NOVO OMO - para maior limpeza economia! "Brilhe como dona-de-casa”! Modernize economicamente, seu sistema de lavar roupas. Mude hoje para o NOVO OMO, o moderno detergente! 
O produto apresentado na propaganda foi um dos sabões em pó a chegar ao Brasil, a primeira marca nacional de sabão em pó que também era fabricado pela Unilever, a atual fabricante dos produtos OMO.

Segundo o Unilever (2014, online), as iniciais do sabão em pó OMO significa: "Old Mother Owl", conhecido como Velha Mãe Coruja, termo utilizado para representar e assimilar as qualidades do animal ao zelo e ao carinho maternal. A ave chegou a ser utilizada como símbolo de representação do produto, na Inglaterra, no início do século 20 chegou a ser estampada em diversas embalagens, porém essa versão nunca chegou ao Brasil.

Com a chegada da marca OMO no país, grande parte das donas de casa passaram a utilizá-lo por oferecer em uma única embalagem um produto 04 em o1, que lava, alveja, quara e dá brilho ao mesmo tempo. O produto multi-funções ficou muito conhecido, por obter sua cor azul tanto no produto quanto nas embalagens. Sua difusão foi muito grande no país, ao facilitar a vida das brasileiras que, com o seu surgimento, deixaram de usar o conhecido anil, usado para alvejar as roupas. A cor azul utilizada tanto no produto, quanto nas embalagens, é considerada como marca registrada e como estratégia de marketing, pois sempre que se pensa em sabão azul logo vem à imagem do produto OMO.

No anúncio, há uma frase de destaque levando o leitor a pensar nessa hipótese de lavar roupas sem sabão, como sendo uma ideia quase impossível. Pela concepção dialógica da linguagem, é possível afirmar que há uma voz feminina presente, no enunciado representando a voz da mulher consumidora do produto, a própria dona de casa questionando a possibilidade de se lavar sem utilizar sabão. Em sequência, há a resposta do enunciador da propaganda: "NOVO OMO! Lava roupas no mesmo molho e dá brilho à brancura".

Evidencia-se, desse modo, a atitude responsiva ativa concebida por Bakhtin, pois, como todo enunciado requer uma resposta. Nesse caso, há um possível questionamento de uma consumidora e, em sequência, a resposta do enunciador desse discurso, denotando um diálogo. Por meio desses enunciados, antecipa-se a possível reação da mulher, ou seja, sua surpresa diante da constatação dos efeitos do produto veiculado.

O estilo considerado como escolhas linguísticas no enunciado: "NOVO OMO é diferente e o mais aperfeiçoado que existe! o3 bons punhados formam um molho de espuma abundante, que lava montanhas de roupas e dá brilho à brancura!" que significa que não é comum, que é extraordinário e que realiza milagres. Enuncia-se, portanto, que OMO é capaz de limpar como se fosse um milagre, pelo fato de facilitar todo o procedimento de lavar roupas, pois anteriormente, era possível somente por meio do sabão comum (em pedaços, de pedra).

Afirma-se ainda que OMO seja melhor que os demais, tornando estes antiquados, ou seja, ultrapassados. Esse discurso revela a necessidade de convencer o consumidor, mostrando-lhe características inovadoras de um produto recente no mercado, reafirmando, assim, a concepção bakhtiniana de que o enunciado está sempre situado em um determinado contexto histórico-social, atendendo às necessidades enunciativas do momento. 
De outro, OMO que também é um sabão, mas diferente, pois, por meio das escolhas lexicais tais como "diferente, abundante, e dá brilho à brancura", sobrepõe suas características, alcançando as concepções de um produto superior, avançado, o "milagre azul". Há também as afirmações de que o produto contém todos os valores positivos agregados.

O enunciatário é instado durante todo o anúncio, por meio do emprego do imperativo "Brilhe", juntamente com os verbos "modernize" e "lave", conjugados no modo imperativo, evidenciando a intenção de convite, desafio ou de sugerir que a prova seja feita e que o consumidor possa visualizar essa limpeza por meio desse novo produto. Os anúncios buscavam introduzir hábitos da higiene, saúde, beleza e cuidados com o lar, sendo voltados para o público feminino com o intuito de tratar a modernidade e praticidade, como propagandas comerciais de cosméticos, cigarros, produtos de limpezas e eletrodomésticos.

Durante o processo da "criação da identidade feminina", a publicidade teve e tem um papel fundamental, pois apresentou valores, mudanças e desenvolvimento da imagem feminina desde tempos antigos até a atualidade.

Com a propaganda, a mulher passou a ser público-alvo de consumo, devido às novas tecnologias que eram oferecidas e apresentadas, facilitando, assim, sua vida por meio dos produtos oferecidos e tornando-a uma mulher moderna da época. Tudo começou quando o ferro a vapor passou a ser substituído pelo ferro elétrico, o fogão preparado a lenha pelo fogão a gás, a batedeira, a enceradeira, o liquidificador, o tanquinho, secador de cabelos, aspirador de pó, panelas de pressão e os produtos de embalagens plásticas trouxeram à vida das donas de casa um grande conforto e praticidade.

Podemos considerar que a cor azul do OMO simboliza a água, que é transparente, límpida e pura, sendo capaz de limpar todos os resíduos e impurezas, deixando sempre tudo mais claro e harmonioso. O emprego do imperativo em "Brilhe" tem a função de sugerir o uso do novo "produto milagroso", enquanto o verbo "modernizar" evidencia que quem utilizar o produto, torna-se uma dona de casa atualizada, avançada. No anúncio, há também a imagem destacada da embalagem, pois a propaganda está em preto e branco, e apenas a caixa está na cor azul, destacando a simbologia cromática da empresa e do produto.

Podemos considerar que o anúncio se mantém nas cores preta e branca, como cores prevalentes não por ser uma propaganda antiga, mas para reforçar a imagem do produto, focalizando, desse modo, a clareza das roupas, deixando-as "mais limpas" e mais atraentes ao olhar do enunciatário. As cores parecem mais escuras sobre o branco, mais claras sobre o preto, pois o branco e os tons claros intensificam as tonalidades que estão sobre elas e o preto, enquanto os tons escuros absorvem e reduzem a potência das cores que são superpostas. A imagem da mulher, dona de casa segurando "toalhas" brancas toda contente e feliz, constrói a ideia de que a utilização do produto garante a alegria nesse afazer doméstico devido a seu resultado final, tornando este trabalho mais prazeroso. 
Ainda, a mulher que não sabia realizar os afazeres domésticos e que não possuía nenhum dote, não era digna de um bom casamento ou respeito de marido, caso conseguisse algum.

Percurso histórico da mulher Antigamente, as mulheres não tinham o direito de se expressar, eram submissas, deviam se casar, serem mães e dedicavam-se totalmente ao lar. Essa vocação era um traço fundamental da feminilidade da época, era um processo de educação das mulheres. Desde a infância, a mulher era comandada e tinha seus atos decididos pelo pai, em seguida pelo marido e, por fim, pelos filhos, tendo que, muitas vezes, suportar o descaso da sociedade. Hábitos como aprender a cozinhar, lavar, passar, costurar, bordar, construir e preparar o enxoval, ouvir os sermões do padre, acompanhar a mãe às compras, ao varejo e à missa eram muito comuns na construção educacional da mulher (PRIORE, 2000). Ao se tornarem jovens, passavam a viver sob uma constante vigilância da família e, principalmente, da sociedade, pois era necessário manter os bons costumes para garantir uma boa imagem e também a ética e moral da família e da jovem. A evolução das mulheres aconteceu, por meio de muitas lutas em prol de direitos e ideais, sendo que, a partir do século XVII, iniciaram os primeiros movimentos feministas. Um grande exemplo de revolução da mulher é a Sóror Juana Inés de la Cruzy Arbaje (México, 1651-1695), que não quis se submeter ao casamento e à maternidade, pois gostaria de se dedicar aos estudos e, assim, conseguiu seu objetivo, destacando-se por seus próprios méritos de escritora.
Ela era ousada e insubmissa, questionou o sistema imposto da época, pois a Igreja não concordava com o fato de estudar assuntos que não fossem religiosos.

Assim, é possível verificar, por meio das ações dessa mulher, a busca pela liberdade e pela igualdade feminina. $E$, em especial no Brasil, no século XX, o direito ao voto foi alcançado pelas brasileiras em 1932, sendo que as mulheres que lutavam pela igualdade, conseguiram alcançá-la por volta dos anos de 1979 e 1985. Na metade dos anos 80, no campo político, surgiram vários grupos de mulheres trabalhadoras, organizações sindicais, associações feministas que, devido à preocupação de melhoria das condições de vida, lutavam também pela divisão sexual do trabalho. Com isso, conseguiram cargos que antes eram ocupados por homens, como nos sindicatos, na política, nas associações etc. No meio rural, as mulheres também lutaram por seus direitos, pois não havia uma divisão entre as atividades do lar e do trabalho, além da educação dos filhos e a vida social. Ainda nesse sentido, o pai ou o marido extrapolava dentro do lar e se impunha, negando a participação das mulheres em decisões em qualquer ramo.

Entretanto, as mulheres frequentavam a Igreja Católica e, nela, era considerada como o mais importante meio de solidariedade, reagindo contra a injustiça social e reafirmando as condições da mulher ser esposa, mãe e do lar. Nesse contexto, determinados grupos de mulheres não se esqueceram de suas atividades, como também lutaram pela solução dos problemas rurais, como o vínculo a terra, dando força aos produtores. Nos 
anos 80 , muitas mulheres tornaram-se sindicalistas ativas e reivindicaram pela saúde, pela educação, pela melhoria dos serviços coletivos municipais, organizando debates, abaixo-assinados, encontros e manifestações. Entraram para essa luta também as professoras, enfermeiras, assistentes sociais e médicas. Devido a esses movimentos, nos anos 80 , começou-se a reformular a visão que se tinha da mulher por meio de discussões sobre as modificações culturais e jurídicas. Já as mulheres da zona urbana começaram as reivindicações, (PRIORE, 2000) a partir dos anos 60, participando de vários movimentos existentes, como por exemplo, em 1968, do "Movimento Nacional contra a Carestia"; em 1970, do "Movimento de Luta por Creches", em 1975, criaram os "Grupos Feministas" e os "Centros de Mulheres". Nesses grupos, questionavam sobre os papéis das mulheres em seus lares, mas nem sempre tratavam da discriminação no mercado de trabalho.

Tiveram papéis importantes para a redemocratização de códigos jurídicos e leis mais coerentes em relação à vida econômica e social da mulher, além disso, lutavam contra a violência e a discriminação feminina. Surgiu também o grupo chamado "Movimentos de Mulheres Trabalhadoras", em que se evidenciava a vontade de cuidar dos dois mundos: do trabalho e do lar. Essas trabalhadoras acreditavam que havia a necessidade de reformular o conceito de feminilidade e, consequentemente, o da masculinidade, combatendo o machismo. As sindicalistas rurais também lutavam pela igualdade dos sexos. Portanto, o homem deveria modificar sua concepção sobre o machismo e aceitar que a mulher era capaz de assumir responsabilidades iguais as dele, por outro lado, a mulher deveria romper com os traços da submissão, que seria conquistada pelo espaço da igualdade. Mesmo com esses sindicatos, ainda havia o machismo praticado pelos homens, pois, no fundo, entendiam que as mulheres não tinham capacidade suficiente para assumir os cargos relacionados à política. Mesmo assim, as mulheres não se deixaram intimidar e continuaram na batalha por seus direitos. Quando as mulheres começaram a frequentar as escolas, a partir do ano de 1871, puderam ser professoras, pois antes somente os homens podiam estudar. Nos anos 80, muitas mulheres contribuíram nos sindicatos, dentre elas, as professoras ajudaram nessa reformulação. Na Constituição de 1988, surgiram vários direitos trabalhistas para ambos os sexos.

Além de ter ampliado o tempo de licença maternidade, introduziu-se a licença paternidade, limites diferentes de idades para a aposentadoria de ambos os sexos, direito à mulher ser chefe de família, reciprocidade no casamento e igualdade entre eles, além de a mulher ter o direito de registrar em seu nome títulos de propriedades de terra. Também começaram a mostrar as discriminações que sofriam: os assédios sexuais nos locais de trabalho, o acesso aos cargos empregatícios não eram somente por ter baixa escolaridade ou não ter especialização adequada, as diferenças salariais marcantes entre os sexos, a menor participação feminina em atos públicos etc, todos por meio de dados estatísticos (PRIORE, 2000). 
O gênero feminino nas propagandas $\mathrm{Na}$ sociedade, desde os tempos mais antigos até a atualidade, existiram grande diferenças apresentadas entre o homem e a mulher. $O$ termo "sexo" era utilizado para distinguir o homem da mulher, mas com o passar do tempo essa atribuição foi dada ao gênero que tem como função tratar a identidade atribuída a uma pessoa de acordo com seu caráter biológico, sendo o gênero feminino para a mulher e masculino para o homem. A mulher, como já apresentamos anteriormente, sempre foi considerada um ser menos privilegiado que o homem, teve menos direitos e até mesmo foi tratada como um ser inferior em relação ao homem, ou seja, deveria ser completamente submissa e destinada somente ao lar com o papel de esposa/mãe. Entretanto, com passar do tempo, a figura feminina ganhou espaço e foi se modificando pouco a pouco. A partir dos anos 50, iniciaram-se os primeiros movimentos feministas com a propagação da mulher no mercado de trabalho e, é a partir desse momento, que as primeiras agências de propagandas foram instaladas no Brasil (CONFORTIN, 2003). Houve uma grande repercussão nesse período, pois grande parte das propagandas tratavam da imagem feminina ou se dirigia como foco principal. Os anúncios buscavam introduzir hábitos da higiene, saúde, beleza e cuidados com o lar, sendo voltados para o público feminino com o intuito de tratar a modernidade e praticidade, como propagandas comerciais de cosméticos, cigarros, produtos de limpezas e eletrodomésticos.

\section{A tríade RETórica}

O processo argumentativo pressupõe uma organização de imagens mútuas que vão sendo construídas ao longo de todo discurso entre locutor e alocutário. Verifica-se na publicidade a construção dos efeitos de sentido, proporcionando uma eficácia discursiva a partir do funcionamento dos três elementos da retórica grega: $\mathrm{O}$ ethos, o páthos e o lógos. Assim, o ethos é o caráter que o orador deve assumir para inspirar confiança no auditório, pois sejam quais forem seus argumentos lógicos, eles não obtêm sem essa confiança. Acrescenta (SANTANA NETO, 2005, p.21): "O ethos visa à influência afetiva, pretendida e exercida pelo locutor sobre o alocutário, com a finalidade de nele exercitar afetos suaves, visando obter a benevolentia". Dessa forma, ele deve preencher as mínimas condições de credibilidade, mostrar-se sensato, sincero e simpático. Ethos é um termo ético, moral, a imagem que o orador deve ter diante do auditório, mesmo que não seja a "verdadeira". O ethos será o caráter psicológico e não moral, que o orador deve assumir. Já o páthos, segundo (REBOUL,2004, p.48): "[...] É o conjunto de emoções, paixões e sentimentos que o orador deve suscitar no auditório com seu discurso." Nesse contexto, a análise dos sentimentos e das paixões é derivada da retórica. Assim, ao falar de ethos, fala-se de orador, ao se falar em páthos, fala-se de auditório e, por fim, ao se falar em lógos, diz-se respeito à argumentação do discurso.

O lógos tem visibilidade nas referidas propagandas, indicado pelo argumento dos verbos: "Aproveite", "Participe", "Incentive"e "cesse", a palavra procura mostrar 
imparcialidade, mas durante todo o percurso demonstra o contrário. E, assim, para obter o assentimento do auditório, utiliza estratégias para persuadir, apelando para a razão, em toda a sua dimensão de palavra pensada. A propaganda publicitária, por exemplo, que remete a um contexto atual, ao qual a imagem feminina era algo quase inatingível, difícil de ser alcançado, justificando o oferecimento oportunidades. Hoje, talvez com novo panorama histórico, as instituições da indústria e marketing abordam outros interesses para despertar e persuadir o público-alvo que antes era menos valorizado talvez pelo simples machismo da sociedade.

\section{Praticidade e modernidade: A união PERFEITA!}

As propagandas de produtos de limpeza, na maioria das vezes, colocou a mulher como público-alvo principal. Sua participação era e ainda é de grande importância para esse tipo de publicidade, pois é a responsável pelas tarefas de limpeza e de manutenção da casa, e que ainda está, em grande proporção, a cargo delas, tornando, assim, símbolo de representação para esse tipo de mercado e comércio. Mesmo na atualidade, em que, em alguns casos, as despesas e as tarefas domiciliares são divididas entre marido e esposa, a mulher ainda é considerada fundamental e até mesmo insubstituível, para lavar, passar, cozinhar, limpar e pela organização geral.

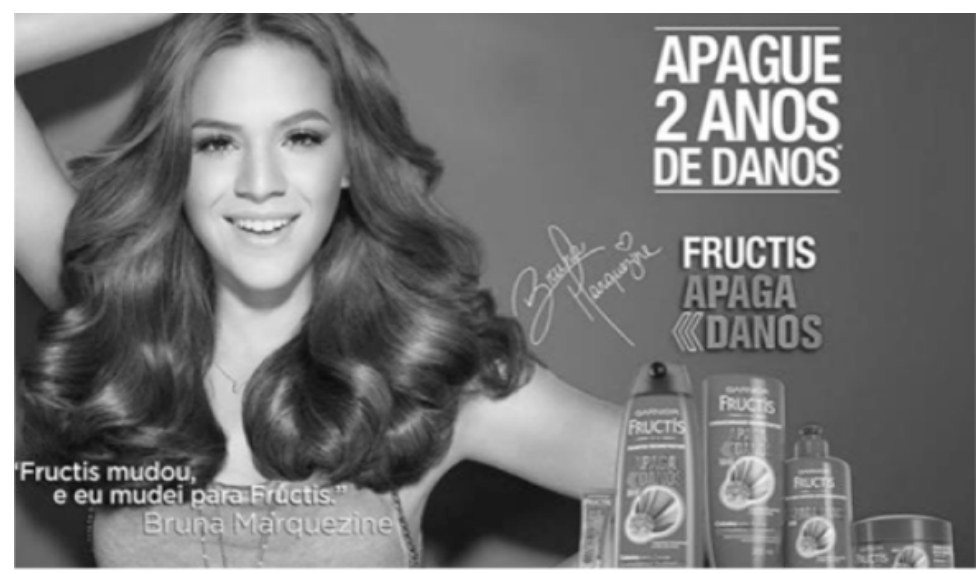

Fonte: http://www.tetereinaldim.com.br/blog/2014/10/resenhacreme-de-tratamento-apaga-danos-garnier-fructis/ 
O pathos e o ethos da retórica aristotélica estão presentes na figura da Bruna Marquezine. O primeiro atinge o público por conta do carisma da atriz, que é querida por boa parte dos brasileiros, e, portanto, com a imagem dela na propaganda, as pessoas vão analisar melhor a proposta da marca. O segundo encontra-se na confiança que a figura de Marquezine passa, por ser uma personalidade que está constantemente na mídia e representar atualmente um padrão de beleza no país. Isso influencia a atitude do público com a sua recomendação do produto. E, além da confiança passada por Bruna, muitas mulheres gostariam de ter um cabelo como o seu, e acreditam que comprando os cosméticos

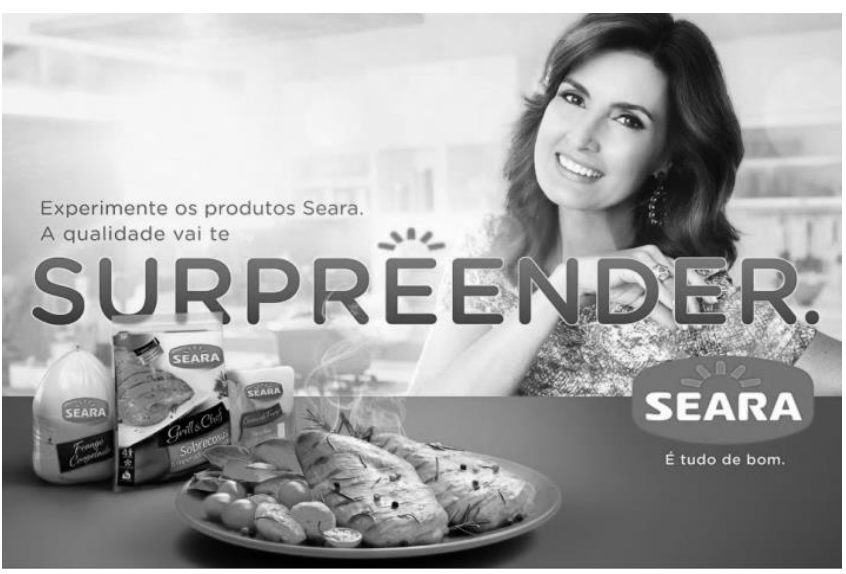

Fonte: http://grandesnomesdapropaganda.com.br/anunci inteligente e uma ótima jogada de uma marca que há muito tempo não era tão comentada e procurada no Brasil.

\section{Análise de Peça Publicitária - Seara} da marca, alcançarão esse objetivo. Logo, este é também um argumento emocional que atinge o público feminino.

O logos encontra-se na seguinte declaração de Bruna "Fructis mudou e eu mudei para Fructis". Isso pode convencer o público a experimentar a nova linha da marca, mesmo que já tenha usado e não aprovado, pois mostra que o produto melhorou a ponto de Marquezine escolhê-lo para usar, em meio a tantos outros. Nessa campanha, há também a presença do maravilhoso, já que faz as mulheres acreditarem que terão uma vida próxima à da atriz se utilizarem os produtos da linha Apaga Danos e que independente do cabelo que têm, podem deixá-lo impecável e sem sinal de danos como o da foto apenas usando os itens da marca.

A ideia de colocar Bruna Marquezine como garota propaganda foi muito 
despertando irracionalmente a fome no público. A cor avermelhada do anúncio prevalece, alinhando-se a do logotipo da marca, afirmando, assim, a disposição dos elementos verbais. Há uma identificação com a marca, pois o público analisa o produto de acordo com Fátima Bernardes, que transmite uma imagem de uma mulher séria.

Peça Publicitária - "Porque se sujar faz bem" $\mathrm{OMO}$

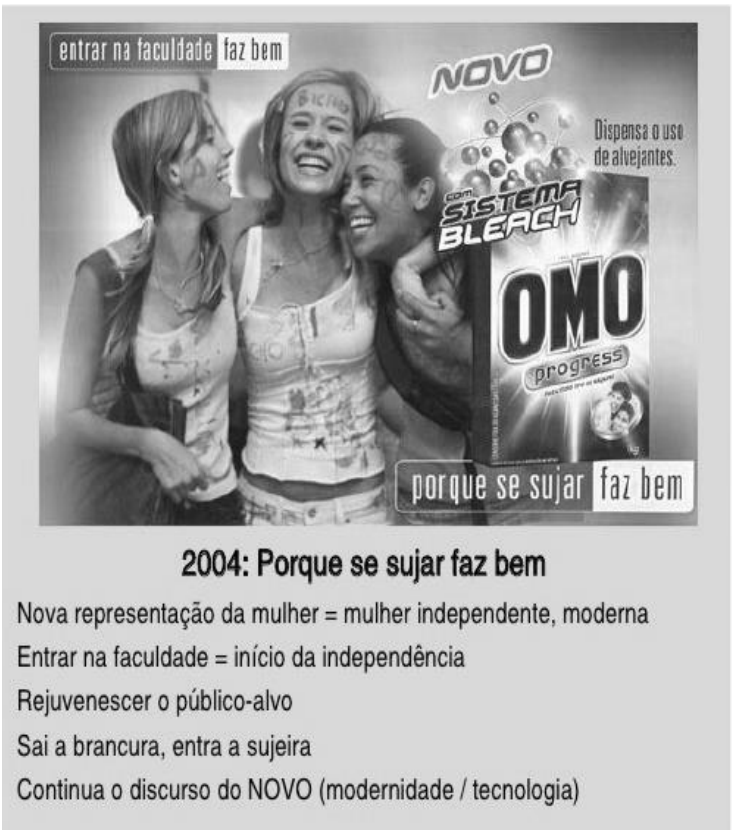

Fonte: http://www.historiaunilever.com.br/ unilever/timeline/produto/omo

Em 1957, a marca OMO, de origem inglesa, foi lançada no Brasil pela Lever, nome adotado pela filial da Unilever no País até 1960. A campanha"Porque se sujar faz bem", lançada em 2004, pela OMO MULTIAÇÃO, apresenta os critérios da retórica aristotélica, assim como mecanismos de persuasão para atingir o público alvo. Nas peças analisadas, a marca intenta um despertar emocional no público-alvo, o que torna perceptível o PATHOS. Feita com mulheres jovens, a campanha retrata a mulher independente, suscitando sentimentos favoráveis, que facilitam a aceitação da tese presente no slogan. $\mathrm{O}$ argumento sensibiliza o consumidor e quebra resistências, uma vez que o faz refletir sobre a importância de ser mulher moderna. Ainda mostram jovens comemorando a entrada na Universidade Pública.

E o que mais importa neste momento não é o que elas usam, porque OMO limpa toda a sujeira. É simplesmente uma passagem feliz e elas sabem que faz parte da vida. Vemos mais mulheres (jovens) felizes, pois conquistaram seu espaço na sociedade e em breve no mercado de trabalho.

Por um tempo, as campanhas da marca eram voltadas para o quesito funcional do produto, mas o foco mudou e passou a sensibilizar o coração das consumidoras. Dando ênfase à importância do brincar, a OMO firmou uma preocupação com a educação, o que culminou no "Projeto Entrar na Faculdade", entre outras iniciativas da marca, que demonstram responsabilidade social e dá maior credibilidade ao produto, eis o Ethos.

O Logos está nesse ideal "ousado" de permitir a sujeira. Encarado como reflexo de uma sociedade que na época é 2004 e já mostra que mulheres conquistaram e estão conquistando mais espaço em Universidades no mercado de trabalho. Recheada de brincadeira e diversão, o argumento é forte, já que a fase do vestibular e aprovação, todos sabem que é uma passagem árdua, mas os 
resultados veem depois e todas ficam felizes, de fato, uma ligação com a modernidade e tecnologia, com o discurso do novo. As cores, a colocação das frases no canto da imagem, dando ênfase à fotografia, são recursos estilísticos que tornam perceptível a forte presença do argumento emocional. A frase: "NOVO OMO PROGRESS, PORQUE SE SUJAR FAZ BEM" que, além do slogan está na peça, gera uma identificação, pois aproxima o público ao afirmar que a marca quer, assim como os pais, que seu filho (a) ultrapasse barreiras e tenha um futuro promissor. Quem hoje é mãe ou pai, com certeza, vai pensar a infância que teve e, consequentemente, sobre a infância que quer que seu filho (a) tenha, pois sabe que isso refletirá na vida adulta dele (a).

A sujeira da roupa toma a forma das adolescentes é um estímulo aos sentidos (nesse caso a visão). Uma vez que ativa a percepção do público, a imagem traz um conteúdo implícito que remete novamente ao slogan, e ajuda a enfatizar outra frase presente no anúncio: "Saia da brancura e entre na sujeira". Com peças publicitárias leves, a campanha, de forma bem sucedida, associa cuidado e incentivo e faz adolescentes, mulheres e jovens comemorar uma nova etapa da vida. Didático-pedagógica, a peça publicitária faz a apologia do fora do comum "Saia da brancura" e relação das adolescentes com a frase "entra na sujeira".

Bem, o que me interessa como sempre, é o aspecto linguístico da questão. O leitor habitual deste espaço sabe que não raro analiso frases publicitárias, muitas das quais são inteligentes e bem arquitetadas.
O leitor sabe também que, nos grandes vestibulares, é cada vez mais comum a exigência da capacidade de percepção dos mecanismos de construção e dos efeitos de frases como a da publicidade do sabão em pó.

Vamos aos fatos, pois. Qual é o sentido que logo se depreende da frase em questão? Não é difícil perceber: um jovem ou uma jovem se suje ao passar no vestibular Mas, a coisa não para por aí, visto que, por trás desse sentido que se percebe de imediato, há outro, em que o " $s$ " deixa de ser pronome reflexivo ("se sujar" = "sujar a si próprio") e passa a ter valor de conjunção condicional ("se sujar" = "caso suje").

É evidente que, para que se materialize o segundo sentido, é preciso supor que o detergente em pó esteja implícito como sujeito da forma verbal "faz". Alguém talvez diga que essa segunda interpretação é forçada, já que, para que a frase de fato tivesse o segundo sentido, seria necessária a presença de duas vírgulas ("Porque, se sujar, faz bem"). Convém lembrar que, nesse tipo de linguagem, não necessariamente se obedece às regras ortodoxas da sintaxe. A linguagem publicitária está mais próxima da literária do que da formal. 
ANÁlISE DA PEÇA Do “O BOTICÁRIo” A SEGUIR:

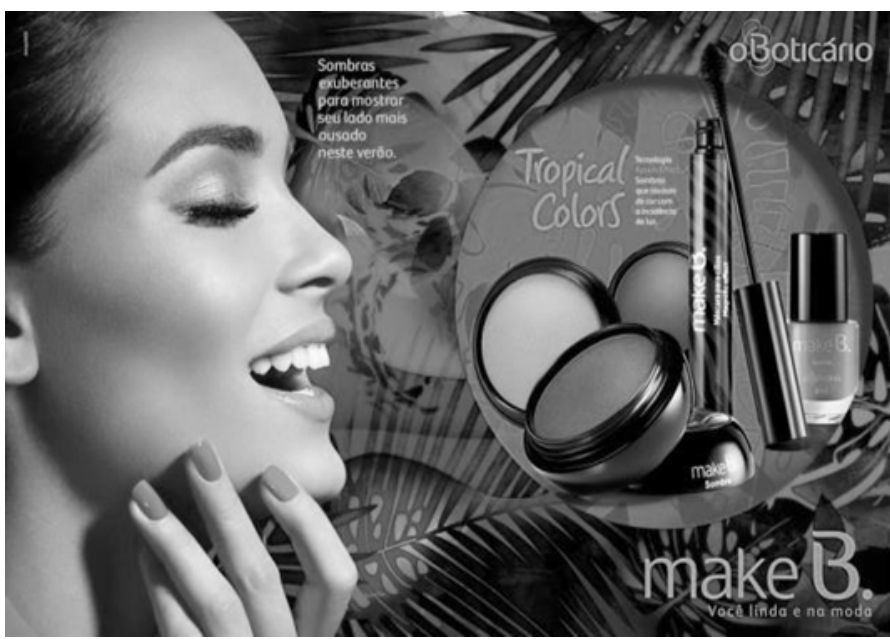

Fonte: http://www.revistafatorbrasil.com.br/ver_noticia. php?not=276932

Ao visualizar a peça publicitária acima, é possível identificar e correlacionar algumas sensações que possuem relação com a identidade do produto à mostra. A alegria, feminilidade e liberdade são apresentadas através da expressão facial da modelo e das cores abertas. Ao optar por uma modelo jovem, a marca atingiu jovialidade. A figura da mulher e a pose fotografada conferem sensualidade, felicidade ousadia e beleza. Um tropicalismo se nota pela mistura de cores tropicais e pelo desenho de folhas e temas florais no plano de fundo do anúncio. Essa mudança e mistura das cores fazem com que a peça seja versátil.

Esse conjunto de características, que são transmitidas aos consumidores, condizem com os valores que a marca quer apresentar e isso contribui, positivamente, para efetividade da peça. A marca (O Boticário) é conhecida por ter um compromisso com a beleza, e por fabricar produtos para todas as idades e sexos. Suas campanhas buscam beleza, leveza e atingir seu público alvo: A classe média e alta da população.

A linha MAKE B. (retratada no anúncio) busca atingir mulheres através da moda (você linda e na moda). O anúncio analisado segue a identidade dessa linha que utiliza como base os valores da cultura contemporânea e traz a valorização da mulher e sua pré-disposição para moda e bem estar.

A peça atinge seu objetivo por manter firme a relação entre os valores que, realmente, passam e os que desejam passar. Além disso, os textos que aparecem no anúncio confirmam a identidade da marca. A cor amarela utilizada nas letras que formam os nomes da marca e da linha garante leveza e alegria. Esse anúncio é veiculado em revistas cujo público alvo engloba o público da marca. A logo fica localizada no final da página direita para se fixar na mente do consumidor que foca seu olhar final para essa região do anúncio.

\section{Considerações finais.}

A mulher destacou-se e ainda continua se destacando devido às grandes conquistas na sociedade, seja nos afazeres cotidianos, seja no mercado de trabalho. Anteriormente, a mulher não possuía direito às escolhas, não tinha voz social, pois, na maioria das vezes, era submissa ao homem, dedicando-se apenas aos afazeres domésticos e cuidados com 
a família. As mulheres eram educadas desde a infância para se tornarem, no futuro, excelentes donas de casa, pois aquelas que não soubessem cozinhar, lavar, passar, não haveriam de arranjar bom marido e bom casamento.

A publicidade reflete essas mudanças, pois, nas propagandas mais antigas, o foco principal eram os afazeres destinados ao lar. Após as lutas contra o preconceito, o machismo, a violência, os abusos sexuais nos locais de trabalho, conquistaram seu espaço na sociedade, sendo mais reconhecidas e valorizadas por suas funções, principalmente no campo profissional. A partir da década de 80, tiveram mais oportunidades de estudar, dando-lhes, assim, condições para entender e discutir sobre vários assuntos, como a política e o futebol, por exemplo, temas esses que eram considerados pertencentes ao universo masculino.

A mulher, na publicidade, é retratada, primeiramente, como a mãe que cuida do lar e dos filhos e que precisa ter menos tempo nos afazeres domésticos. Por isso, há a intenção de convencê-las sobre os valores e capacidades do produto anunciado em relação aos demais existentes no mercado desde então. Portanto, a mulher mãe do lar é diferenciada nas propagandas. Posteriormente, o discurso publicitário passou a mostrar a mulher que cuida de si mesma, dona de si e possui menos tempo ainda para os afazeres domésticos, pois tem de trabalhar, cuidar da família e de si mesma. A partir das propagandas da década de 90, as mulheres são retratadas como batalhadoras por seus ideais, exercendo diferentes funções no trabalho que, antes, somente eram feitas por homens. Assim, o enunciador dos anúncios de produtos de limpeza e alimentícios tem como intuito discursivo conquistar a confiança das mulheres e, para isso, utilizam recursos verbo-visuais diversos como imagens, textos explicativos e expressões, visando persuadi-las por meio da valorização de sua imagem ou das facilidades proporcionadas pelos produtos. Por outro lado, é comum ainda a concepção da mulher ligada aos trabalhos domésticos, em pleno século XXI. Porém isso vem deixando de lado aos poucos.

\section{REFERÊNCIAS}

ARISTÓTELES. Arte retórica e arte poética. Tradução Antônio Pinto de Carvalho. São Paulo: Difusão Europeia do Livro, 1959.

Retórica das paixões. Tradução e notas de Ísis Borges B. da Fonseca. São Paulo: Martins Fontes, 2003.

BAHKTIN, Mikhail. Os gêneros do discurso. In: ___ Estética da criação verbal. 04. ed. São Paulo: Martins Fontes, 2003. Cap. III, p. 261-306.

BRAIT, Beth. Estilo. In: (Org.). Bakhtin: Conceitos-chave. São Paulo: Contexto, 2007. p. 79 - 102.

BAUDRILLARD, Jean. 0 sistema dos objetos. São Paulo: Perspectiva, 2002.

BERTOMEU, João Vicente Cegato. Criação da propaganda impressa. São Paulo: Futura, 2002.

DEL PRIORE, Mary (org.) História das crianças no Brasil. 06. ed. São Paulo: Contexto, 2007. CONFORTIN, Helena ET AL. Discurso e gênero: A mulher em foco. In: GHILARDILUCENA. 
Maria Inês (Org.). Representações do feminino. 01. ed. São Paulo: Átomo, 2003.

GARBOGGINI-SIQUEIRA, Flailda. A mulher margarina. Uma representação dominante em comerciais de TV nos anos 70 e 80. 1995. Dissertação (Mestrado em Multimeios). Campinas, UNICAMP, 1995.

LUCENA, Maria Inês Ghilardi (Org.). Representações do feminino. Campinas: Átomo, 2003.

OMO. Unilever, Histórias das marcas, Centro de histórias Unilever, 2001. Disponível em:<http:// www.unilever.com.br/aboutus/centro_de historia_unilever/historiadasmarcas/omo/> Acesso em 20 Jun. 2014.

REBOUL, Olivier. Introdução à retórica. Trad. Ivone Castilho Benedetti. São Paulo: Martins Fontes, 2004.

SANTANA NETO, João Antonio de. Processos argumentativos: Estudo retórico de textos didáticos. Salvador: Quarteto, 2005.

SIGNIFICADO da cor azul. Significados.com. br. Disponível em:<http://www.significados. com.br/cor-azul/> Acesso em 03 Ago. 2014.

SIGNIFICADO da cor amarela. Significados. com.br. Disponível em:<http://www. significados.com.br/cor-amarela/> Acesso em 31 Ago. 2014.

SIGNIFICADO da cor vermelha. Significados. com.br. Disponível em:<http://www. significados.com.br/cor-vermelha/> Acesso em 31 de ago. 2014.

STREY, Marlene Neves (Org.). Mulher, estudos de gênero. São Leopoldo: Unisinos, 1997.

Recebido para publicação em 8 abr. 2017. Aceito para publicação em 30 set. 2017. 